\title{
Occurrence of peste des petits ruminants and its increasing threat to Europe
}

\author{
WIESŁAW NIEDBALSKI
}

Department of Foot-and-Mouth Disease, National Veterinary Research Institute, Wodna 7, 98-220 Zduńska Wola, Poland

\section{Niedbalski W. \\ Occurrence of peste des petits ruminants and its increasing threat to Europe \\ Summary}

Peste des petits ruminants (PPR) is a highly contagious disease of small ruminants that leads to high morbidity and mortality, and thereby results in devastating economic consequences to the livestock industry. It is caused by the PPR virus (PPRV), which belongs to the genus Morbilivirus in the family Paramyxoviridae. PPR was first recorded in early 1942 in Ivory Coast, West Africa. In the following years, the disease extended its distribution to other parts of the world and now circulates throughout Northern, Eastern and West Africa, as well as Asia - in particular, China, Central Asia, Eurasia, the Indian subcontinent and the Middle East. The molecular epidemiology of PPRV, based on the sequence comparison of a small region of either the $\mathbf{N}$ or the F gene, has revealed the existence of four distinct lineages (I-IV) of the virus. Until June 2018, PPR had never been detected in Europe, with the exception of the European part of Turkish Thrace. However, on $24^{\text {th }}$ June 2018 the Bulgarian authorities reported cases of PPR in sheep in the village of Voden, Bolyarovo municipality of Yambol region, on the border with the Thrace region of Turkey. It was the first occurrence of PPR in Bulgaria and in the European Union (EU). The source of PPR infection in Bulgaria is not clear, it could have been the illegal movement of animals, contaminated materials or humans, e.g. refuges. Due to the increased risk of introduction of PPR from North Africa and Turkey to neighbouring regions, the European Food Safety Authority (EFSA) has recently published a report assessing the risk of PPR spreading in Europe. According to a scientific opinion by the EFSA, the spread of PPRV in the territory of the UE could occur by the illegal transport of infected animals or infected animal products. In order to limit the spread and impact of PPR outbreaks in Europe, rapid detection, movement restriction, prompt culling of infected herds and disinfection measures should be introduced immediately. The control and eventual eradication of PPR is now one of the top priorities for the Food and Agriculture Organization (FAO) and the World Organization for Animal Health (OIE). In 2015, the international community agreed on a global strategy for PPR eradication, setting 2030 as a target date for elimination of the disease.

Keywords: peste des petits ruminants, global occurrence, threat to Europe

Peste des petits ruminants (PPR) is a highly contagious viral disease of domestic and wild small ruminants caused by the peste des petits ruminants virus (PPRV), which belongs to the genus Morbilivirus in the family Paramyxoviridae (11). The PPRV causes disease in goats and sheep, as well as in wild ruminants, such as gazelle, deer, antelope, Nubian ibex, gemsbok and others. Although goats and sheep are the primary hosts for the virus, goats seem to be more susceptible to disease than sheep (14). PPRV attacks the alimentary, respiratory and lymphoid systems after initial multiplication in the retropharyngeal mucosa and viraemia. The clinical findings and pathology are identifiable to necrosis and, in the case of the respiratory system, to cellular proliferation (12). The incubation period is typically 4-6 days, but may range from 3 to 10 days. During the acute stage of disease, animals show pyrexia $\left(40-41{ }^{\circ} \mathrm{C}\right)$ with effects on the general state: the animals become depressed or restless, anorexic and develop a dry muzzle and dull coat. Watery nasal and lachrymal discharges gradually become mucopurulent with excessive salivation. Erosive lesions formed in the oral cavity become necrotic. In later stages of the disease, animals develop diarrhoea and coughing with laboured abdominal breathing (16). Dehydration, emaciation, dyspnoea, hypothermia and death of animals can occur within 5-10 days of infection. Abortions are often observed during PPR outbreaks, caused by PPRV alone or in combination with other pathogens (1). The morbidity rate can reach $100 \%$, with a high case fatal- 
ity rate in the acute form of disease. The mortality rate can range between 10 and $90 \%$, depending on the host status, and if animals recover, there is no persistent infection or carrier state (31).

The PPRV particle size has been determined to be between 400 and $500 \mathrm{~nm}$ (11). During virus budding, the viral envelope is derived from the infected cell membrane, and it is studded with glycoprotein spikes on the viral envelope consisting of viral fusion (F) and haemagluttinin $(\mathrm{H})$ glycoproteins. The PPRV genome consists of non-segmented single stranded negativesense RNA encapsidated by nucleoprotein $(\mathrm{N})$ forming a helical nucleocapsid, in combination with the RNA-dependent RNA polymerase and the co-factor phosphoprotein to form the ribonucleoprotein (RNP) complex. RNPs are located within the virus envelope and appear as helices with a herringbone appearance. The matrix protein $(\mathrm{M})$ located on the inner surface of the envelope bridges the RNP and cytoplasmic tails of the membrane glycoproteins. The PPRV genome $(15,948$ nucleotides in length) consists of six transcriptional units that encode for six proteins, N, P, M, F H and L (4). Transcriptional units are separated from each other by conserved intergenic trinucleotides. The PPRV genome 3' and 5' termini sequences are complementary and conserved and play an important role as regulatory elements in the replication, transcription and packaging of the RNA genome during virus propagation (7).

PPR was first recorded in early 1942 in Ivory Coast, West Africa (20). In the following years, the disease extended its distribution in other parts of the world and now circulates throughout Northern, Eastern and West Africa, as well as Asia - in particular China, Central Asia and Eurasia, the Indian subcontinent and the Middle East $(8,29,30)$ (Fig. 1). In the $21^{\text {st }}$ century, the disease has extended its boundaries southwards in Africa as far as southern Tanzania (2008), Zambia (2015), the Democratic Republic of Congo (2012) and Angola (2012). PPR has also been reported across North Africa, including Tunisia (2006), Morocco (2008 and 2015) and Algeria (2011 and 2016). Morocco started implementing a mass vaccination campaign in 2008, which was continued in 2010-2011. In Eastern Africa, all countries have been infected in recent years, and a regional strategy has been developed. Currently, vaccination campaigns are launched mostly in response to disease outbreaks, but wider campaigns have also been conducted in several countries, such as Kenya and Somalia, with active support of the FAO. Following the introduction of the disease in a few new countries, the Southern African Development Community (SADC) developed a regional PPR control strategy in 2010 in order to immediately control PPRV circulation in these countries and thus to prevent the disease from spreading to adjoining countries and ultimately to eradicate PPR from the SADC region. As a result, South Africa is officially recognised by the OIE as PPR-free. The first incursion of PPR into Tibet and China occurred in 2007. Since the end of 2013, 22 of the 31 provinces of China have been infected (www. fao.org/docrep/017/ aq236e.pdf). The first clinical PPR outbreak in Turkey was not reported until 1999. Thereafter, the disease has been reported in South-eastern Anatolia, Eastern Anatolia and Mediterranean regions of Turkey on a regular basis. The number of outbreaks varies: it was maximal in 2000 (43 outbreaks) and then decreased, but new peaks were observed in 2006 and 2007 (94 and 95 outbreaks, respectively) (http://www.oie.int/ RR-Europe/eng/Projects/Gftads10-SANCO-PPR.pdf). The movement of live infected animals facilitated the spread of the disease to other parts of this country. In Thrace, the European part of Turkey, PPRV infection was confirmed for the first time in 2000, and since then PPR outbreaks have been reported annually, except in 2009 and 2014 (21, 30). In Georgia, the first occurrence of PPR was reported in February 2016 (www. oie.int/eng/session2016/sg84/02-Monday/Europe/ PPR in Georgia.pdf). In Asia, almost all countries of the South Asian Association for Regional Cooperation (SAARC), such as Afghanistan, Pakistan, Bangladesh, Bhutan, India, Nepal and Sri Lanka, have been infected. In Central Asia, few countries have been infected, but the exact situation is not always well known. The PPR situation in the Middle East has recently been favourable, but some countries have been infected and the precise situation in some others should be better assessed. In three countries of this region (Iraq, Syria and Yemen) with large small ruminant populations, the current political disturbances are hindering surveillance and control programmes for PPR. This represents a major risk to neighbouring countries. Summarizing the occurrence of PPR between 2007 and early 2015, 63 countries/territories in Africa, the Middle East and Asia reported PPR present or suspected at least once (19) (Fig. 1).

Identification of the lineage of PPRV is essential for understanding its epidemiology and for the control of PPR. The molecular epidemiology of PPRV, based on the sequence comparison of a small region of either the $\mathrm{N}$ or the $\mathrm{F}$ gene, has revealed the existence of four distinct lineages (I-IV) of the virus $(3,8,26)$ (Fig. 2). Historically, the four lineages follow a geographical distribution: lineages I and II are found in Western and Central Africa, lineage III is present in eastern Africa and in the southern part of the Middle East; lineage IV is distributed in the Middle East and southern Asia. Previously, lineage IV was restricted mainly to the Middle East and Asia, but since the 1990s, this linage has been found in African countries, including: Cameroon, Central African Republic, Sudan, Morocco, Egypt, Tunisia, Algeria and Uganda. Currently, in a large zone encompassing Sudan, Ethiopia, Somalia and Kenya, lineage IV is slowly replacing PPRV lineage III $(24,29,30)$. The apparent expansion of 


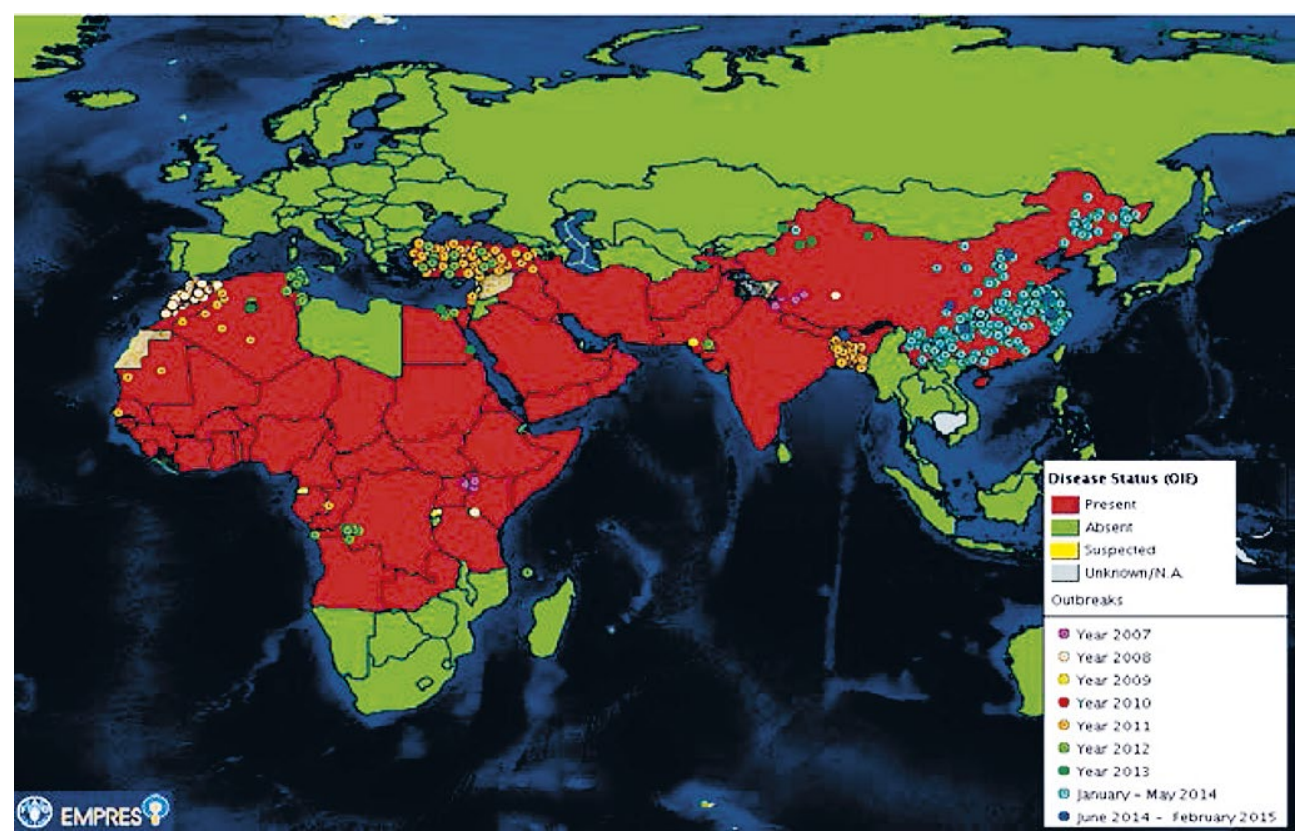

Fig. 1. Global PPR epidemiological situation and occurrence of outbreaks between 2007 and early 2015. According to OIE WAHIS and FAO EMPRES (19)

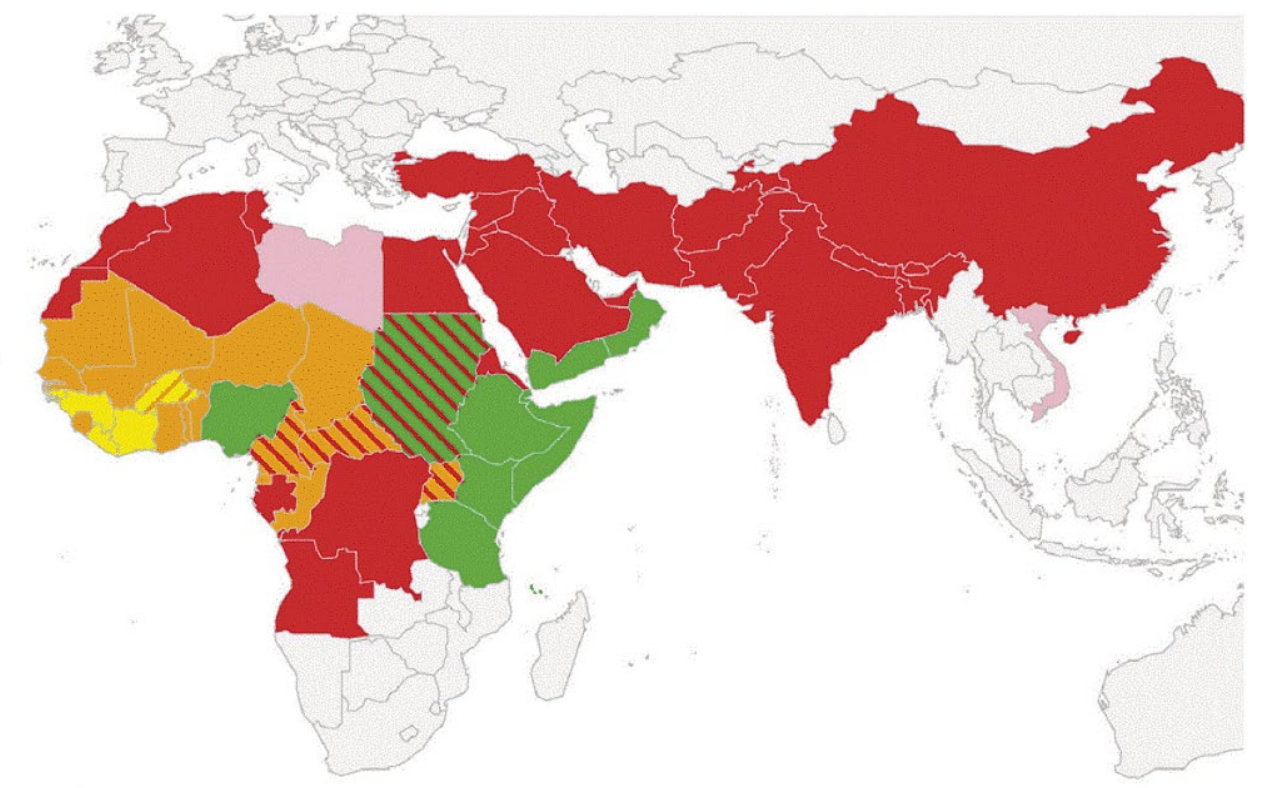

originated in western Africa and then spread to eastern Africa, the Middle East and Asia. From the phylogenetic analysis, two clear groups (of Asian and African origin) of PPRV lineage IV were observed. Asian lineage IV viruses have also been distributed into two subgroups: the Indian vaccine strain (Sungri 96) and Izatanagar strains are found to be more closely related to strains circulating in Turkey, whilst Chinese strains form a separate cluster. The China (Tibetan) outbreak viruses from 2007 are more closely related to the viruses circulating in India, whilst the viruses characterized from the 2014 outbreaks across China are more closely related to PPRV from Kazakhstan (22).

PPRV is transmitted to close in-contact susceptible animals through exhaled aerosols, particularly during coughing, or through clinical excretions (lachrymal, nasal, saliva and faeces) (2). The virus is found in all kinds of secretions from approximately 3 to 22 days post infection. The virus can be spread over large distances through the movement of infected animals for trade or during migration, particularly animals incubating the disease without clinical signs. PPRV is temperature labile and is readily inactivated outside its host in a dry environment. The virus is considered sensitive to heat, ultraviolet light and $\mathrm{pH}$ lower

Fig. 2. Distribution of PPRV lineages. Modified, according to Albina et al. (3)
Positive serology

No declaration
Asian lineage IV across Africa is supported by a constant increase in the incidence of PPR, suggesting an increase in its virulence (26). A recent full-genome phylogeographic analysis has indicated that Nigeria was the geographic origin of the most recent common ancestor of PPRV (29). The estimated median time to the most recent common ancestor (TMRCA) of PPRV in the Bayesian method was estimated to be about 1900 years (95\% Highest Posterior Density (HPD) 1805-1962) (30). Furthermore, PPRV lineages I, II, and III were predicted to originate within Africa and lineage IV probably emerged in India, suggesting that PPRV than 5.5 and higher than 10 , and it does not survive in the environment, unless in shaded conditions, where it can survive for up to 72 hours. Infected and recovered animals develop life-long protective immunity with no carrier state, but virus can spread in animals as a mild virulent form that can later lead to severe disease when transmission occurs to naive susceptible populations (15). Host factors, such as age, sex, breed and season, may also play a role in disease outbreaks. Sheep and goats are the primary hosts for PPRV, with a few reports of a subclinical infection with PPRV in camels, cattle, buffalo and pigs, which, however, 
are not thought to be capable of excreting virus and contributing to the epidemiology of the disease (30). The exact role of wildlife in the epidemiology of PPR is not clear. A recent serosurveillance at the interface of wildlife and domestic small ruminants in Tanzania revealed a spill-over of virus from domestic infected ruminants to wildlife, which needs further investigation (28).

The recent reports of PPR in countries previously considered free from PPR and the reoccurrence of disease in countries that had experienced PPR earlier, are thought to be caused mainly by the introduction of new live small ruminants incubating the disease or by illegal movements of infected animals or their products from endemic countries to free countries. An example were outbreaks reported in Angola, where PPR was noted for the first time in 2012 after importation of sheep and goats from Congo. Morocco was free from PPR until 2008, however in the mid-July 2008 the outbreak of disease has been detected in the central part of this country. It was probably introduced through the movement of live infected animals during intense trade in northern Morocco immediately before the Islamic "Festival of Sacrifice." After mass vaccination campaigns during 2009-2011, PPR outbreaks were not seen until June 2015, when they reoccurred. A serosurveillance study in young animals (less than 8 months of age) in 2012 revealed no antibody prevalence against PPRV, and therefore it is possible that the circulation of virus had ceased. The cause of recent outbreaks in Morocco is unknown, but they are believed to be due to the transboundary movement of infected animals. Mauretania has been endemic for PPR since the 1980s, and disease outbreaks in 2012 were shown to be caused by a lineage II PPRV, similar to the Senegalese outbreak. PPR outbreaks in Algeria in 2010 were caused by a lineage IV virus, and more recent outbreaks were reported in Ghardaia province during 2013 and reoccurred in 2016, indicating continuous circulation of the disease in Algeria (4). The southern desert areas bordering the Sahel countries favour the movement of infected animals and the spread of PPR in Algeria. In Tunisia, serological evidence of PPRV infection was first reported in 2006, and clinical cases were described in 2012-2013 (32). It is possible that an uncontrolled introduction of infected animals through the southern border of Tunisia resulted in these new outbreaks. The movement of live animals from third countries in the Mediterranean Basin and Black Sea areas into the European Union (EU) is currently forbidden by EU animal health legislation on the import of live animals from countries where PPR is endemic. Therefore the legal importation of these small ruminants from North African countries and Turkey to Europe is not possible. However, some movements of live sheep and goats from Turkey to Bulgaria and Hungary were recorded by the European Statistical Office (Eurostat) in 2011.
A large number of these small ruminants were also transferred within Turkey, particularly from southern and western Turkey, endemic with PPR, to free areas, such as Istanbul and Thrace. Although North African countries generally do not import live sheep and goats, an informal trade and animal movement through the borders is ongoing, which favours the spread of PPR. The movement of live animals from Spain, France, Italy and Romania to Morocco, Algeria and Tunisia takes place particularly towards the end of religious festivals, such as Ramadan and the month preceding the Hajj Islamic pilgrimage. Therefore, it is possible to spread PPRV from North African countries to the European countries through fomites. This could occur when vehicles carrying livestock return to the EU after the delivery of animals to infected areas or farms and when no biosecurity measures are applied. That is why the proper cleaning and disinfection of vehicles transporting livestock is required before the vehicles return to Europe. The disease may also spread through the uncontrolled movement of infected animal products, including meat products, in which the virus can survive 2-3 days, carried by tourists and visitors from countries that are at high risk of PPR. Moreover, small ruminants may be smuggled in vehicles into Europe for domestic consumption. Therefore, the illegal movement of infected animal products represents a further potential threat of disease spreading to PPR-free countries.

Until June 2018, PPR had never been detected in Europe, with the exception of the European part of Turkish Thrace. However, on 24 ${ }^{\text {th }}$ June 2018 the Bulgarian authorities reported a case of PPR in sheep in the village of Voden, Bolyarovo municipality of Yambol region, on the border with the Thrace region of Turkey. In a flock of 540 sheep and goats, two animals tested positive and one died, with disease recognised by the National Reference Laboratory for capripox and then confirmed by the EU Reference Laboratory for PPR (EURL-PPR), CIRAD-BIOS-UMR-117, Montpellier, France. It was the first occurrence of PPR in Bulgaria and in the EU (http://www.oie.int/ wahis_2/public/wahid.php/Diseaseinformation/WI). A second outbreak was reported on $28^{\text {th }}$ June in a herd of 9 goats and 151 sheep (of which 10 were infected) in the village of Kosti in the Burgas region in the east of the country. This new infected region is located 160 $\mathrm{km}$ from the first three infected herds in the Yambol region. This raises questions about the origin of this second outbreak: was there a link to the first outbreak or were there multiple introductions from Turkey? Further four PPR outbreaks, with 15 cases of clinical disease in sheep, were reported on $17^{\text {th }}$ July in villages Krainovo, Strandzha and Sharkovo in the Yambol region, and then on $18^{\text {th }}$ July 2018 one PPR outbreak was recorded in the Bolyarovo municipality, Yambol region. It was not clear how disease had spread to Bulgaria. It is believed that the source of PPR infection in Bulgaria could have 
been the illegal movement of animals, contaminated materials or humans, for example, refuges. In addition to the illegal movement of PPRV-infected animals or animal products, the directed connectivity of the Turkish endemic region to the neighbouring Bulgaria is another potential route of transmission. Turkey hosts the same community of wild ruminants as Europe, including representatives of the Caprinae (wild goats, chamois) and Cervidae. Wild goats are of importance because they are the most widespread and abundant wild ruminants in Europe. These wild ruminants can serve as a bridging species for PPRV transmission between distant populations of infected and healthy domestic sheep and goat populations.

Due to the increased risks of introduction of PPR from North Africa and Turkey to neighbouring regions, the European Food Safety Authority (EFSA) has recently published a report assessing the risk of introduction of PPR into the EU (18). According to a scientific opinion presented by the EFSA, the spread of PPRV in the territory of the UE could occur by the illegal transport of infected animals or infected animal products. The risk of that depends on the prevalence in the country of origin and the number animals illegally moved. The extent of the spread would depend mainly on the time during which it is undetected, the farm density, as well as the frequency and distance of travel of animals. If PPR enters EU areas with a dense goat population, but low sheep density, it may spread rapidly undetected, since goats are considered more susceptible than sheep. Regarding the risk of PPR becoming endemic in animal populations in the EU, although PPR is endemic in several countries neighbouring on or close to the EU, the lack of data on disease transmission in the EU makes it impossible to extrapolate international data directly to the European situation to make a quantitative assessment of the risk of endemicity. Given the control measures foreseen by the current EU policy, PPR is not likely to become endemic in the EU. Effective measures limiting the spread of PPR in the UE include prompt culling of infected herds, rapid diagnosis, movement restrictions and disinfection of environmental materials. According to the EFSA Panel on Animal Health and Welfare (AHAW), since clinical signs of PPR are not disease-specific and clinical disease is not reliable, disease should be confirmed by laboratory testing. The most common, rapid, specific and sensitive laboratory PPR recognition techniques are immunocapture enzyme-linked immunosorbent assay (ELISA) for PPR antigen detection and realtime polymerase chain reaction (PCR) for detection of viral RNA $(9,25)$. The most reliable and rapid test for antibody detection is a competition ELISA based on a monoclonal antibody directed against the virus nucleoprotein (27). The effectiveness of PPR laboratory diagnosis can be greatly influenced by the integrity of the sample received, often affected by the conditions of its collection and transportation. Recently, an immunochromatographic lateral flow device has been developed and validated under field conditions as a pen-side test using a monoclonal antibody specific to the virus $H$ protein (10).

With regard to specific immunoprophylaxis against PPRV infection, only live attenuated vaccines are available, which are safe and highly efficacious against all known isolates of PPRV, but do not support the Differentiating Infected from Vaccinated Animals (DIVA) principle (17). These live attenuated vaccines are thermolabile and need maintenance of an effective cold chain during delivery to the field, but they are considered to be the best choice for disease prevention in endemic regions (6). However, in non-endemic regions under threat, such as Europe, this vaccine is usually not recommended by veterinary authorities, so inactivated vaccines remains the only viable alternatives. One such vaccine provided sterile immunity and was found to resist challenge with virulent PPRV, though two doses of the vaccine were required (13). Recently, some recombinant subunit vaccines based on the baculovirus expression system, vaccinia virus and poxvirus vectors have been developed (23). Possible DNA vaccines based on recombinant techniques have been shown to be efficacious, but are still at the experimental stage. The vaccines currently available to protect small ruminants against PPRV infection are sufficient to carry out an eradication campaign, but there is little doubt that improvement of vaccines would reduce the costs of control, making eradication more readily achievable in areas with limited financial resources. In terms of preparedness, the AHAW Panel recommends designing and implementing a regional PPR control strategy, especially in endemic countries or where PPR has occurred and been controlled, relying on coordinated mass vaccination and post-vaccination monitoring as well as efficient active surveillance measures. In order to limit the spread and impact of PPR outbreaks in Europe, rapid detection, movement restrictions, prompt culling of infected herds and disinfection measures should be introduced immediately (18).

It is worth noting the socioeconomic importance of PPR. It is one of the most economically important animal diseases in areas that rely on small ruminants. The disease affects the lives of about 300 million of the world's poorest people whose livelihoods depend on small ruminants. Many small holders in poor developing countries in Asia and Africa depend on goats and sheep for nutrition and livelihood. Moreover, these animals are a source of regular income, acting as "mobile banks" to depend on in times of hardship and cash urgencies in poor households. PPR causes annual global losses estimated at US\$ 1.4 to US\$ 2.1 billion. There are indirect losses, too, as loss of livestock causes pastoralists and farmers to migrate away from their lands and cultures in search of alternative livelihoods. 
Eradication of PPR is therefore highly relevant to poverty alleviation. That is why the control and eventual eradication of PPR is now one of the top priorities for the Food and Agriculture Organization (FAO) and the World Organization for Animal Health (OIE). After the successful eradication of rinderpest (RP) - an equally devastating livestock disease - in 2011, the FAO and the OIE began mobilizing support for a similar effort aimed at complete elimination of PPR in the world. In 2015 , the international community agreed on a global strategy for PPR eradication, setting 2030 as a target date for elimination of the disease. PPR eradication efforts will involve a combined approach of strengthening countries' veterinary health services and systems for disease surveillance, vaccination campaigns and awareness raising. It will require the support of many institutions, such as national veterinary services of particular countries, research and development organizations and vaccine manufacturing companies.

In conclusion, the recent PPR outbreaks in Bulgaria demonstrate that there is a threat of PPR spreading to the territory of other European countries. The risk of PPR spreading in Europe could be reduced by raising the awareness of the disease; training farmers and veterinary staff in recognising PPR; increasing the knowledge about the transportation of animals and animal products; implementation of adequate biosecurity measures, including potential surveillance, at relevant borders; and maintaining stocks of vaccine that allows for immunological differentiation of infected from vaccinated animals.

\section{References}

1. Abubakar M., Ali Q., Khan H. A.: Prevalence and mortality rate of peste des petits ruminants (PPR): possible association with abortion in goat. Trop. Anim. Health Prod. 2008, 40, 317-321.

2. Abubakar M., Arshed M. J., Zahur A. B., Ali Q., Banyard A. C.: Natural infection with peste des petits ruminants virus: a pre and post vaccinal assessment following an outbreak scenario. Virus. Res. 2012, 167, 43-47.

3. Albina E., Kwiatek O., Minet C., Lancelot R., Servan de Almeida R., Libeau G.: Peste des petits ruminants, the next eradicated animal disease. Vet. Microbiol. 2013, 165, 38-44.

4. Baazizi R., Mahapatra M., Clarke B. D., Ait-Oudhia K., KhelefD., Parida S. Peste des petits ruminants (PPR): A neglected tropical disease in Maghreb region of North Africa and its threat to Europe. PLoS One 2017, 12, e0175461

5. Bailey D., Chard L. S., Dash P., Barrett T., Banyard A. C.: Reverse genetics for peste-des-petits ruminants virus (PPRV): promoter and protein specificities. Virus Res. 2007, 126, 250-255.

6. Balamurugan V., Sen A., Venkatesan G., Bhanuprakash V., Singh R. K.: Protective immune response of live attenuated thermo-adapted peste des petits ruminants vaccine in goat. Virusdisease 2014, 25, 350-357.

7. Banyard A. C., Baron M. P., Barrett T.: A role for virus promoters in determining the pathogenesis of rinderpest virus in cattle. J. Gen. Virol. 2005, 86, 1083-1092.

8. Banyard A. C., Parida S., Batten C., Oura C., Kwiatek O., Libeau G.: Global distribution of peste des petits ruminants virus and prospects for improved diagnosis and control. J. Gen. Virol. 2010, 91, 2885-2897.

9. Bao J., Li L., Wang Z., Barrett T., Suo L., Zhao W., Liu Y., Liu C., Li J.: Development of one-step real-time RT-PCR assay for detection and quantitation of peste des petits ruminants virus. J. Virol. Methods 2008, 148, 232-236.

10. Baron J., Fishbourne E., Couacy-Hyman E., Abubakar M., Jones B. A., Frost L., Herbert R., Chibssa T. R., Van't Klooster G., Afzal M., Ayebazibwe C., Toye P., Bashiruddin J., Baron M. D.: Development and testing of a field diagnostic assay for peste des petits ruminants virus. Transbound. Emerg. Dis. 2014, $61,390-396$
11. Baron M. D., Diallo A., Lancelot R., Libeau G.: Peste des petits ruminants virus. Adv. Virus Res. 2016, 95, 1-42.

12. Constable P. D., Radostits O. M., Gay C. C., Hinchcliffe K. W.: Veterinary Medicine, a textbook of the diseases of cattle, horses, sheep, pigs and goats, $10^{\text {th }}$ ed.,Saunders 2007, pp. 1242-1243.

13. Cosseddu G. M., Polci A., Pinoni C., Capobianco Dondona A., Iapaolo F., Orsini G., Izzo F., Bartone G., Ronchi F. G., Di Ventura M., El Harrak M., Monaco F.: Evaluation of humoral response and protective efficacy of an inactivated vaccine against peste des petits ruminants virus in goats. Transbound. Emerg. Dis. 2016, 63, e447-52, doi. 10.1111/tbed.12314.

14. Couacy-Hymann E., Bodjo S. C., Danho T., Koffi M. Y., Libeau C., Diallo A.: Early detection of viral excretion from experimentally infected goats with peste-des-petits ruminants virus. Prev. Vet. Med. 2007, 78, 85-88.

15. Couacy-Hymann E., Bodjo C., Danho T., Libeau G., Diallo A.: Evaulation of the virulence of some strains of peste-des-petits-ruminants virus (PPRV) in experimentally infected West African dwarf goats. Vet. J. 2007, 173, 178-183.

16. Diallo A.: Control of peste des petits ruminants and poverty alleviation? J. Vet. Med. B Infect. Dis. Vet. Public Health 2006, 53, 11-13.

17. Diallo A., Minet C., Le Goff C., Berhe G., Albina E., Libeau G., Barnett T.: The threat of peste des petits ruminants: progress in vaccine development for disease control. Vaccine 2007, 25, 5591-5597.

18. European Food Safety Authority AHAW Panel (EFSA Panel on animal health and welfare). Scientific opinion on peste des petits ruminants. EFSA Journal, 2015, 13, 3985, 94 pp., doi: 10.2903/j.efsa.2015.3985

19. FAO and OIE International Conference for PPR: Control and eradication of peste des petits ruminants (PPR), Global strategy for the control and eradication of PPR, Abidjan, Cote D'Ivoire, 31 March-2 April 2015 (www.fao.org/3/ a-i4460e.pdf)

20. Gargadennec L., Lalanne A.: La peste des petits ruminants. Bulletin des Services Zoo Techniques et des Epizooties de l'Afrique Occidentale Francaise $1942,5,16-21$

21. Güler L., Sevik M., Hasöksüz M.: Phylogenetic analysis of peste des petits ruminants virus from outbreaks in Turkey during 2008-2012. Turk. J. Biol 2014, 38, 671-678

22. Kock R. A., Orynbayev M. B., Sultankulova K. T., Strochkov V. M., Omarova Z. D., Shalgynbayev E. K., Rametov N. M., Sansyzbay A. R., Parida S.: Detection and genetic characterization of lineage IV peste des petits ruminants virus in Kazakhstan. Transbound. Emerg. Dis. 2015, 62, 470-479.

23. Kumar N., Barua S., Riyesh T., Tripathi B. N.: Advances in peste des petits riminats vaccines. Vet. Microbiol. 2017, 206, 91-101.

24. Kwiatek O., Ali Y. H., Saeed I. K., Khalafalla A. I., Mohamed O. I., Obeida A. A., Abdelrahman M. B., Osman H. M., Taha K. M., Abbas Z., El Harrak M., Lhor Y., Diallo A., Lancelot R., Albina E., Libeau G.: Asian lineage of peste des petits ruminants virus, Africa. Emerg. Infect. Dis. 2011, 17, 1223-1231.

25. Libeau G., Diallo A., Colas F., Guerre L.: Rapid differential diagnosis of rinderpest and peste des petits ruminants using an immunocapture ELISA. Vet. Rec. 1994, 134, 300-304.

26. Libeau G., Diallo A., Parida S.: Evolutionary genetics underlying the spread of peste des petits ruminants virus. Anim. Front. 2014, 4, 14-20.

27. Libeau G., Prehaud C., Lancelot R., Colas F., Guerre L., Bishop D. H., Diallo A.: Development of competitive ELISA for detecting antibodies to the peste des petits ruminants virus using a recombinant nucleoprotein. Res. Vet. Sci. 1995, 58, 50-55.

28. Mahapatra M., Sayalel K., Muniraju M., Eblate E., Fyumagwa R., Shilinde L., Mdaki M., Keyyu J., Parida S., Knock R.: Spillover of peste des petits ruminants virus from domestic to wild ruminants in the Serengeti ecosystem, Tanzania Emerg. Infect. Dis. 2015, 21, 2230-2234

29. Muniraju M., Munir M., Parthiban A. R., Banyard A. C., Bao J., Wang Z., Ayebazibwe C., Ayelet G., El Harrak M., Mahapatra M., Libeau G., Batten C., Parida S.: Molecular evolution of peste des petits ruminants virus. Emerg Infect. Dis. 2014, 20, 2023-2033.

30. Parida S., Muniraju M., Mahapatra M., Muthuchelvan D., Buczkowski H. Banyard A. C.: Peste des petits ruminants. Vet. Microbiol. 2015, 181, 90-106.

31. Pope R. A., Parida S., Bailey D., Brownlie J., Barret T., Banyard A. C.: Early events following experimental infection with peste-des-petits ruminants virus suggest immune cell targeting. PLoS One 2013, 8(2): e55830, doi: 101371/ journal.pone. 0055830

32. Sghaier S., Cosseddu G. M., Ben Hassen S., Hammami S., Ammar H. H., Petrini A., Monaco F. Peste des petits ruminants virus, Tunisia, 2012-2013. Emerg. Infect. Dis. 2014, 20, 2184-2186.

Corresponding author: dr hab. Wieslaw Niedbalski, assoc. prof., Wodna 7, 98-220 Zduńska Wola; e-mail: wieslaw.niedbalski@piwzp.pl 